\title{
Current trends in the treatment of pneumonia due to
}

\section{multidrug-resistant Gram-negative bacteria [version 1; peer}

\section{review: 2 approved]}

\author{
Richard R. Watkins ${ }^{1,2}$, David Van Duin ${ }^{3}$ \\ ${ }^{1}$ Division of Infectious Diseases, Cleveland Clinic Akron General, Akron, OH, 44302, USA \\ 2Department of Medicine, Northeast Ohio Medical University, Rootstown, $\mathrm{OH}, 44272$, USA \\ ${ }^{3}$ Department of Medicine, University of North Carolina, Chapel Hill, NC, 27514, USA
}

V1 First published: 30 Jan 2019, 8(F1000 Faculty Rev):121

https://doi.org/10.12688/f1000research.16517.1

Latest published: 06 Feb 2019, 8(F1000 Faculty Rev):121

https://doi.org/10.12688/f1000research.16517.2

\section{Abstract}

Pneumonia is one of the most common infections worldwide.

Morbidity, mortality, and healthcare costs increase substantially when pneumonia is caused by multidrug-resistant Gram-negative bacteria (MDR-GNB). The ongoing spread of antimicrobial resistance has made treating MDR-GNB pneumonia increasingly difficult. Fortunately, there have been some recent additions to our antibiotic armamentarium in the US and Europe for MDR-GNB, along with several agents that are in advanced stages of development. In this article, we review the risk factors for and current management of MDR-GNB pneumonia as well as novel agents with activity against these important and challenging pathogens.

\section{Keywords}

Enterobacteriaceae, Pseudomonas aeruginosa, Acinetobacter baumannii, antibiotics

\section{Open Peer Review}

Approval Status

1

2

version 2

(revision)

06 Feb 2019

\section{version 1}

30 Jan 2019

Faculty Reviews are review articles written by the prestigious Members of Faculty Opinions. The articles are commissioned and peer reviewed before publication to ensure that the final, published version is comprehensive and accessible. The reviewers who approved the final version are listed with their names and affiliations.

1. Frank Schweizer, University of Manitoba, Winnipeg, Canada

2. Dean Winslow, Stanford University School of Medicine, Stanford, USA

Any comments on the article can be found at the end of the article. 
Corresponding author: Richard R. Watkins (WatkinR2@ccf.org)

Author roles: Watkins RR: Conceptualization, Writing - Original Draft Preparation, Writing - Review \& Editing; Van Duin D: Writing Original Draft Preparation, Writing - Review \& Editing

Competing interests: RRW serves on an advisory board and speakers' bureau and has received research support from Allergan. DvD serves on advisory boards for Allergan, Achaogen, Shionogi, Tetraphase, Sanofi Pasteur, MedImmune, and Astellas and has received research funding from Steris Inc. and Scynexis.

Grant information: The author(s) declared that no grants were involved in supporting this work.

Copyright: $\odot 2019$ Watkins RR and Van Duin D. This is an open access article distributed under the terms of the Creative Commons Attribution License, which permits unrestricted use, distribution, and reproduction in any medium, provided the original work is properly cited.

How to cite this article: Watkins RR and Van Duin D. Current trends in the treatment of pneumonia due to multidrug-resistant Gram-negative bacteria [version 1; peer review: 2 approved] F1000Research 2019, 8(F1000 Faculty Rev):121 https://doi.org/10.12688/f1000research.16517.1

First published: 30 Jan 2019, 8(F1000 Faculty Rev):121 https://doi.org/10.12688/f1000research.16517.1 


\section{Introduction}

Infections due to multidrug-resistant Gram-negative bacteria (MDR-GNB) pose a serious and increasing threat to human health. This is particularly true in the pathogenesis of pneumonia, where escalating rates of antimicrobial resistance (AMR) have been associated with excessive morbidity, mortality, and healthcare costs ${ }^{1}$. It is well recognized that timely and effective therapy is vital for improving outcomes, especially for pneumonia that is hospital acquired ${ }^{2}$. The choice of initial antibiotic therapy for pneumonia is based on several factors, including recommendations from guidelines, national and local antimicrobial susceptibility data, and patient characteristics such as allergies and renal function. For many years, the backbone of treatment for pneumonia has been the $\beta$-lactam class of antibiotics, including the third- and fourth-generation cephalosporins and $\beta$-lactam/ $\beta$-lactamase inhibitor combinations like piperacillin/tazobactam ${ }^{3}$. Unfortunately, the ongoing spread of extended-spectrum $\beta$-lactamases (ESBLs) and carbapenemases such as Klebsiella pneumonia carbapenemase (KPC) has begun to limit the clinical effectiveness of $\beta$-lactam agents over the last decade ${ }^{4,5}$.

The diagnosis of pneumonia can be challenging, especially in cases of hospital-acquired pneumonia (HAP) and ventilatorassociated pneumonia (VAP). Indeed, pulmonary infiltrates on imaging in critically ill patients are common and can be due to non-infectious etiologies, including atelectasis, acute respiratory distress syndrome (ARDS), congestive heart failure (CHF), pulmonary hemorrhages, and pulmonary infarction. Moreover, upper airways and endotracheal tubes of hospitalized patients are often colonized by MDR-GNB and their presence does not necessarily mean that they are the cause of the pulmonary abnormalities seen on imaging studies. A careful clinical assessment is therefore imperative when evaluating for pneumonia, especially in patients who have had a prolonged hospitalization. The current HAP/VAP guidelines from the Infectious Diseases Society of America are an excellent reference for help with diagnosing these cases ${ }^{2}$.

The initial approach to pneumonia is most often empirical because results of antimicrobial susceptibility testing typically take 48 to 72 hours. Rapid diagnostic tests (RDTs), including molecular methods that identify specific resistance genes or automated microscopy that can quickly determine antibiotic susceptibility, have great potential for guiding empiric antibiotic therapy. But current RDTs have limitations and most have not been validated for respiratory secretions ${ }^{6}$. Deciding on an appropriate empirical regimen can be difficult because clinicians must consider the benefits of starting therapy early versus the harms of unnecessary coverage. Indeed, inappropriate antimicrobial treatment or delays in starting appropriate treatment in VAP are associated with increased morbidity and mortality ${ }^{7}$. Once susceptibility testing results are available, empiric antibiotic therapy should be deescalated. Most cases of MDR-GNB pneumonia can be successfully treated with 7 days of therapy ${ }^{2}$.

Several risk factors for MDR-GNB pneumonia have been identified. These include prior infection or colonization with MDR-GNB, antibiotic therapy in the past 90 days, poor functional status performance, hospitalization for more than 2 days in the past 90 days, occurrence 5 or more days after admission to an acute hospital, receiving hemodialysis, and immunosuppression ${ }^{8,9}$. Moreover, prior receipt of carbapenems, broad-spectrum cephalosporins, and fluoroquinolones has been associated specifically with MDR Pseudomonas aeruginosa ${ }^{10}$.

Recently, the high mortality and mortality associated with MDRGNB pneumonia along with limited treatment options have led to a resurgence in the use of the nephrotoxic drug colistin ${ }^{11}$. Fortunately, several new antibiotic agents with activity against MDR-GNB, including plazomicin, ceftazidime/avibactam, and meropenem/vaborbactam, have become available. This review discusses new antibiotic options for MDR-GNB and those in late stages of clinical development and provides guidance for their use in treating MDR-GNB pneumonia.

\section{Multidrug-resistant Enterobacteriaceae}

Similar to other MDR-GNB, MDR Enterobacteriaceae are usually encountered as the cause of healthcare-associated pneumonia and are less commonly seen in community-acquired pneumonia (CAP). In a recent large intensive care unit (ICU) study of 75 US centers, the most common Enterobacteriaceae isolated from patients with pneumonia were Klebsiella pneumoniae, Enterobacter spp., and Escherichia coli, which accounted for $12 \%, 8 \%$, and $7 \%$ of all bacterial isolates included in the study, respectively ${ }^{12}$. Important MDR Enterobacteriaceae that cause pneumonia include those bacteria that produce AmpC enzymes, ESBL, or carbapenemases or a combination of these. AmpC and ESBL producers are usually resistant to most, if not all, cephalosporins. ESBL but not AmpC producers are variably inhibited by $\beta$-lactamase inhibitors. Also, AmpC enzymes are frequently found in Enterobacter spp. and may be induced by antibiotic treatment, leading to treatment-emergent resistance ${ }^{13}$. As AmpC enzymes do not effectively hydrolyze cefepime, AmpCproducing Enterobacteriaceae often retain in vitro susceptibility to cefepime ${ }^{13}$. The management of pneumonia caused by carbapenem-resistant Enterobacteriaceae (CRE) is the most challenging. In a longitudinal cohort study of patients with CRE, pneumonia and bloodstream infections (BSIs) were found to be associated with the highest mortality rates ${ }^{14}$. When compared with comparable patients colonized with CRE, CRE pneumonia had an excess hospital mortality of $27 \%$ and adjusted hazard ratio of 3.44 (95\% confidence interval $[\mathrm{CI}] 1.80-6.48, p<0.001$ ) for time to death ${ }^{14}$. Risk factors for MDR Enterobacteriaceae as a cause of pneumonia overlap with those of other MDR organisms and include prior exposure to antibiotics, healthcare exposure, and use of medical devices such as urinary catheters ${ }^{15,16}$.

An excellent comprehensive review on the therapy of MDR Enterobacteriaceae was recently published by Rodríguez-Baño et al. and the reader is referred to this review for additional background $^{17}$. It is important to note that the MERINO trial (Meropenem versus piperacillin-tazobactam for definitive treatment of bloodstream infections due to ceftriaxone non-susceptible Escherichia coli and Klebsiella spp.) had not yet been published at the time of that review. In the MERINO trial, patients with BSI caused by ceftriaxone-resistant Enterobacteriaceae were 
randomly assigned to receive either piperacillin/tazobactam or meropenem in an open-label non-inferiority design ${ }^{18}$. The mechanism of resistance in these isolates was an ESBL in about $85 \%$ and $\mathrm{AmpC}$ in about $10 \%$. In contrast to some observational studies, the mortality in piperacillin/tazobactam-treated patients was significantly higher as compared with those treated with meropenem $(12 \% \text { versus } 4 \%)^{18,19}$. A total of 12 out of 379 patients had pneumonia as a source of BSI in this study. Similarly, in a randomized controlled trial comparing cefepime versus imipenem in the treatment of pneumonia, a decreased efficacy of cefepime was noted in patients infected with ESBL-producing Enterobacteriaceae $^{20}$. Based on these data, carbapenems should be considered first-line treatment for pneumonia caused by ESBL-producing Enterobacteriaceae. In an observational study of AmpC-producing Enterobacteriaceae BSI, patients who received definitive therapy with piperacillin/tazobactam were compared with a group of patients who received either cefepime or piperacillin/tazobactam. Only $14 \%$ and $20 \%$ of patients had pneumonia as the source of $\mathrm{BSI}^{21}$. Although no statistically significant differences were found, it was notable that the 30-day mortality in the piperacillin/tazobactam-treated patients was $15 \%$ versus $7 \%$ in the meropenem- or cefepime-treated patients ${ }^{21}$. Based on these clinical data and the known hydrolysis of piperacillin by AmpC, piperacillin/tazobactam cannot be considered first-line treatment for AmpC-producing Enterobacteriaceae. As mechanisms of resistance are usually not available to treating clinicians, practically speaking, piperacillin/tazobactam should not be used for pneumonia caused by Enterobacter spp., Serratia spp., or Citrobacter spp.

Whether cefepime can be successfully used in the treatment of pneumonia caused by AmpC-producing Enterobacteriaceae remains unclear. In a propensity-adjusted analysis of observational data on patients with infections caused by AmpC-producing Enterobacteriaceae, treatment with cefepime $(\mathrm{n}=32)$ was compared with meropenem $(\mathrm{n}=32)^{22}$. Pneumonia was present in $53 \%$ and $41 \%$ of cefepime- and meropenem-treated patients, respectively. Overall, no difference in 30-day mortality was seen (odds ratio [OR] 0.63 , 95\% CI $0.23-211$ ), but it should be noted that this OR had a wide CI that included both a fourfold decreased odds of 30-day mortality in cefepime-treated patients and a twofold increased odds ${ }^{22}$. Given the absence of activity of AmpC against cefepime and these limited clinical results, cefepime is a reasonable carbapenem-sparing option for pneumonia caused by AmpC-positive Enterobacteriaceae.

Carbapenem resistance in Enterobacteriaceae can be mediated through carbapenemases, which are usually carried on mobile genetic elements such as plasmids (carbapenemase-producing Enterobacteriaceae, or CPE), or through a variety of other mechanisms such as porin mutations (non-carbapenemase-producing CRE). Important classes of carbapenemases include KPC, New Delhi metallo- $\beta$-lactamases (NDMs), and OXA-48-like carbapenemases $^{23}$. Prior to the availability of newer antibiotics, treatment of invasive CRE infections included the use of polymyxins, tigecycline, and aminoglycosides, often given in combination regimens ${ }^{24}$. More recently, meropenem/vaborbactam, ceftazidime/avibactam, eravacycline, and plazomicin have become available ${ }^{25-27}$. These agents have specific in vitro anti-CRE activity. Plazomicin has broad activity regardless of carbapenemase but is inactivated by $16 \mathrm{~S}$ rRNA ribosomal methyltransferases that are present in some NDM-producing $\mathrm{CPE}^{28}$. Meropenem/ vaborbactam is active against KPC-producing CPE, and avibactam inhibits KPC and OXA-48-like carbapenemases ${ }^{25,29}$. Eravacycline is a fluorocycline antibiotic similar in structure to tigecycline ${ }^{30}$. Eravacycline is unique in the group of recently approved anti-CRE antibiotics in that it has an oral formulation. In addition, there are several other anti-CRE agents in the pipeline, including cefiderocol, imipenem/relebactam, and meropenem/ nacubactam.

With the availability of these new agents, there are some (but no definitive) clinical data available on the best treatment of CRE infections, including CRE pneumonia. In an observational study, patients with CRE infections - caused primarily by KPC producers-who were started on colistin $(n=99)$ were compared with patients who were started on ceftazidime/avibactam $(n=38)^{31}$. In an inverse probability of treatment-weighted analysis, the 30-day mortality in patients on colistin was 32\% versus $9 \%$ (absolute difference $23 \%$, 95\% CI 9\%-35\%; $p=0.001$ ) in those on ceftazidime/avibactam. Pneumonia was present in $24 \%$ and $32 \%$ of patients on colistin and ceftazidime/avibactam, respectively ${ }^{31}$. In a randomized controlled trial, plazomicin was compared with colistin-both given in combination with either tigecycline or meropenem-in CRE BSI $(n=29)$ or pneumonia $(n=8)^{32}$. Plazomicin versus colistin therapy was associated with $2 / 17(12 \%)$ versus $8 / 20(40 \%)$ all-cause mortality at day $28^{32}$. Similarly, meropenem/vaborbactam $(n=28)$ was compared with best available therapy $(n=15)$ for CRE infections, 5 of which were pneumonia $^{26}$. Rates of clinical cure at test of cure visit were $57 \%$ and $27 \%$ in the meropenem-vaborbactam and best available therapy arms, respectively ${ }^{26}$. Based on these data, it is clear that polymyxin-based therapy is inferior to treatment with one of these novel agents. Although only limited numbers of patients with CRE pneumonia were studied, the use of either meropenemvaborbactam or ceftazidime-avibactam in CRE pneumonia is a reasonable approach while awaiting more data. Ceftazidime/ avibactam was shown to be non-inferior to meropenem in a recent large randomized controlled trial of non-CRE pneumonia ${ }^{33}$. Meropenem itself has been used as a comparator agent in many pneumonia studies, and vaborbactam achieves high epithelial lining fluid concentrations ${ }^{34}$. In contrast, in the absence of confirmatory data, plazomicin should not be considered a first-line choice for monotherapy of CRE pneumonia.

\section{Pseudomonas aeruginosa}

The acquisition of MDR $P$. aeruginosa, a significant and increasing cause of HAP/VAP in North America and Europe, is related to both patient factors (for example, older age, previous colonization, recent broad-spectrum antibiotic use, malignancy, and presence of shock) and nosocomial factors (for example, admission to a ward with a high incidence of MDR strains) ${ }^{35}$. Indeed, recent receipt of an anti-pseudomonal antibiotic, especially quinolones and carbapenems, appears to be an important driver of MDR $P$. aeruginosa acquisition ${ }^{10}$. Compared with less-resistant strains, pneumonia due to MDR $P$. aeruginosa is associated with 
longer stays in the ICU, prolonged mechanical ventilation, and greater mortality ${ }^{36}$. Thus, improving the management of MDR $P$. aeruginosa pneumonia must be a priority in order to improve outcomes from both clinical and financial standpoints.

At present, there is no high-grade evidence to guide management decisions for MDR P. aeruginosa pneumonia. Current guidelines recommend combination empiric therapy when AMR is a concern and suggest that aminoglycosides and colistin be avoided if alternative agents are available (low-quality evidence) ${ }^{2}$. An antipseudomonal cephalosporin, carbapenem, fluoroquinolone, or $\beta$-lactam/ $\beta$-lactamase inhibitor is a potential option for initial therapy. Once susceptibility results are available, combination therapy can be de-escalated to monotherapy in most cases. However, combination therapy should be continued for patients in septic shock or at a high risk for death ${ }^{2}$. Patients with VAP due to MDR $P$. aeruginosa that is susceptible to only aminoglycosides or polymyxins should receive both inhaled and systemic antibiotics rather than systemic antibiotics alone ${ }^{2}$. In addition to adequate antibiotic coverage, other factors such as adequate drug dosing, appropriate intervals of drug administration, and duration of therapy (usually 7 days) are important for achieving optimal clinical outcomes. For example, a single-center retrospective study found that mortality was significantly lower in patients with $P$. aeruginosa pneumonia who received extended-infusion cefepime versus standard dosing (20\% versus $3 \%$, respectively; $p=0.03$ ), along with significantly lower length of ICU stay (18.5 versus 8 days, respectively; $p=0.04)^{37}$.

Several new antibiotics with activity against MDR $P$. aeruginosa have become available recently or are in late stages of development. Ceftolozane/tazobactam is a combination of a novel cephalosporin with a modified side chain and a $\beta$-lactamase inhibitor. The potent anti-pseudomonal activity of ceftolozane/tazobactam is attributed to its ability to evade the resistance mechanisms of $P$. aeruginosa, including efflux pumps, reduced uptake through porins, and modification of penicillin-binding proteins (PBPs) ${ }^{38}$. A higher dose ( $3 \mathrm{~g}$ intravenously [IV] every 8 hours) has been recommended for treating pneumonia compared with the currently approved dose (1.5 g IV every 8 hours) based on pharmacokinetic estimates for achieving a more than $90 \%$ probability of target attainment for the 1-log kill target against pathogens with a minimum inhibitory concentration (MIC) of not more than $8 \mathrm{mg} / \mathrm{L}$ in epithelial lining fluid $^{39}$. Of concern is a recent retrospective study from a single center in Germany that reported that $55 \%$ of $P$. aeruginosa isolates were resistant to ceftolozane/tazobactam, which the authors suggested may be due to carriage of the VIM-2 carbapenemase $^{40}$. Notably, ceftolozane/tazobactam lacks activity against Ambler class B (metallo-)carbapenemases, such as VIM and NDM.

Ceftazidime/avibactam, a combination of a third-generation cephalosporin and a novel synthetic non- $\beta$-lactam, $\beta$-lactamase inhibitor, is also ineffective against metallo- $\beta$-lactamases. In pooled data from five randomized controlled trials including one onHAP/VAP (REPROVE), 95 cases of MDR P. aeruginosa were identified $^{41}$. The favorable microbiological response rates at test of cure for MDR P. aeruginosa were $57.1 \%$ for ceftazidime/ avibactam and $53.8 \%$ for comparators, primarily carbapenems ${ }^{41}$. Thus, ceftazidime/avibactam likely has a role as a carbapenemsparing agent for treating MDR $P$. aeruginosa pneumonia. Recent data suggest that ceftazidime/avibactam is a viable option against strains of MDR P. aeruginosa that are resistant to ceftolozane/ tazobactam $^{42}$.

Cefiderocol is a novel siderophore cephalosporin that inhibits cell wall synthesis through the formation of an iron ion complex that penetrates bacteria via a ferric iron transporter system ${ }^{43}$. Cefiderocol has demonstrated potent activity against $\beta$-lactamaseproducing $P$. aeruginosa, including those expressing ESBLs, Ambler class A $\beta$-lactamases, and metallo- $\beta$-lactamases ${ }^{44,45}$. Currently, there is a randomized clinical trial under way for the treatment of HAP comparing the combination of cefiderocol and linezolid with linezolid and meropenem (ClinicalTrials.gov Identifier: NCT03032380 ${ }^{46}$. The novel $\beta$-lactamase inhibitor relebactam inhibits Ambler class A and C $\beta$-lactamases and is in development in combination with imipenem. According to data from a global surveillance program that included Africa, Asia, Europe, Latin America, the Middle East, US/Canada, and the South Pacific, imipenem/relebactam inhibited $90.8 \%$ of all P. aeruginosa isolates and $70.7 \%$ of MDR P. aeruginosa isolates ( $\mathrm{n}=3,708)^{47}$. A study on patients with HAP/VAP is ongoing. Finally, though still in early development, murepavadin is the first member of a novel class of outer membrane proteintargeting antibiotics specifically designed to target $P$. aeruginos $a^{48}$. In a study that included 785 isolates of extremely drug-resistant $P$. aeruginosa, Sader et al. reported that murepavadin showed potent activity against isolates that were non-susceptible to colistin, ceftolozane/tazobactam, or tobramycin or a combination of these $\mathrm{e}^{49}$. These promising findings raise hopes for the further development of murepavadin.

\section{Acinetobacter baumannii}

Most cases of Acinetobacter baumannii pneumonia occur in hospitalized patients, although it is occasionally seen in $\mathrm{CAP}^{50}$. Therefore, the recent report that, after increasing for many years, the rate of AMR in A. baumannii hospital-acquired infections may be leveling off is grounds for cautious optimism ${ }^{51}$. AMR in A. baumannii is the primary reason that clinicians prescribe ineffective empirical antibiotic therapy, often leading to poor outcomes $^{52}$. For example, VAP due to MDR A. baumannii results in significantly lower rates of successful ventilator weaning compared with susceptible strains ${ }^{53}$. A retrospective cohort study that included 175 hospitals found that having pneumonia or sepsis from MDR A. baumannii was significantly associated with receiving inappropriate antibiotic therapy and higher hospital mortality ${ }^{54}$. Thus, it is crucial that risk factors for MDR A. baumannii be recognized early so that appropriate empiric therapy can be rapidly initiated.

When pneumonia due to MDR A. baumannii is suspected (that is, during an A. baumannii outbreak, in an endemic setting, or in a previously colonized patient), combination therapy including a polymyxin should be empirically prescribed until susceptibilities are known ${ }^{55}$. If clinical suspicion for resistance is low, then a carbapenem (except ertapenem, which lacks activity against 
A. baumannii) should be first-line therapy. Many combination therapies for MDR A. baumannii have been investigated and were recently discussed by Vazquez Guillamet and Kollef ${ }^{6}$. Polymyxins remain the backbone of combination regimens. A retrospective cohort study that included patients with pneumonia caused by strains of $A$. baumannii susceptible only to colistin and tigecycline compared three combination regimens: colistin and high-dose sulbactam $(\mathrm{n}=93)$, colistin and tigecycline $(n=43)$, and colistin and high-dose prolonged infusion of a carbapenem $(n=30)^{56}$. The 28-day survival rate and mean length of hospital stay were not statistically different between regimens, whereas an elevated Acute Physiologic Assessment and Chronic Health Evaluation (APACHE) score, delay in receipt of an active regimen, underlying malignancy, and chronic kidney disease were all significantly associated with increased mortality ${ }^{56}$. Using a loading dose of IV colistin for MDR A. baumannii VAP appears to have no significant effect on clinical cure rates or bacteriologic clearance but does increase the risk for nephrotoxicity ${ }^{57}$. The addition of inhaled colistin to systemic therapies has generally showed favorable results, including better microbiological response. A prospective observational study that compared an IV $\beta$-lactam plus IV aminoglycoside, monotherapy with inhaled colistin, and aerosolized colistin plus IV aminoglycoside found no difference in cure rates ${ }^{58}$. Another study in which IV colistin was compared with IV colistin plus inhaled colistin and inhaled colistin alone also found no differences in mortality or clinical cure, and microbiological cure was better in the aerosolized group ${ }^{59}$. Once susceptibility results of $A$. baumannii isolates become available, combination therapy may be de-escalated to monotherapy. However, tigecycline alone should be avoided, as resistance in A. baumannii can develop rapidly ${ }^{60}$.

Although there have been several recent approvals of antibiotics with activity against Gram-negative pathogens (for example, delafloxacin, ceftazidime-avibactam, ceftolozane-tazobactam, and meropenem-vaborbactam), the pipeline is limited for agents effective against MDR A. baumannii (Table 1). Cefiderocol has been shown to have potent in vitro activity against $A$. baumannii and exhibits high stability against carbapenemase hydrolysis ${ }^{61}$. A 52-country collection of clinical isolates obtained between 2014 and 2016 found that 330/368 (89\%) of MDR A. baumannii strains had cefiderocol MICs of not more than $4 \mu \mathrm{g} / \mathrm{mL}^{62}$. Another study evaluated 107 carbapenem-resistant $A$. baumannii isolates from 18 Greek hospitals and determined that the $\mathrm{MIC}_{90}$ of

Table 1. New antibiotics for multidrug-resistant Gram-negative bacteria.

\begin{tabular}{|c|c|c|c|c|}
\hline Drug & Class & $\begin{array}{l}\text { Development } \\
\text { stage }\end{array}$ & Activity & FDA indication \\
\hline Aztreonam/avibactam & $\begin{array}{l}\text { Monobactam/ } \beta \text {-lactamase } \\
\text { inhibitor }\end{array}$ & Phase II & ESBL, KPC, class C $\beta$-lactamase, MBL & Not applicable \\
\hline Cefiderocol & $\begin{array}{l}\text { Siderophore } \\
\text { cephalosporin }\end{array}$ & Phase III & $\begin{array}{l}\text { ESBL, CRE } \\
\text { (class A, B, and D enzymes), } \\
\text { carbapenem-resistant Pseudomonas } \\
\text { aeruginosa, Stenotrophomonas } \\
\text { maltophilia, } \\
\text { and Acinetobacter baumannii }\end{array}$ & Not applicable \\
\hline Ceftazidime/avibactam & $\begin{array}{l}\text { Cephalosporin } / \beta- \\
\text { lactamase inhibitor }\end{array}$ & FDA-approved & $\begin{array}{l}\text { ESBL, KPC, AmpC, some class D serine } \\
\beta \text {-lactamases }\end{array}$ & $\begin{array}{l}\text { HABP/VABP, clAl, } \\
\text { cUTI }\end{array}$ \\
\hline Ceftolozane/tazobactam & $\begin{array}{l}\text { Cephalosporin } / \beta- \\
\text { lactamase inhibitor }\end{array}$ & FDA-approved & ESBL, MDR $P$. aeruginosa & cUTI, clAl \\
\hline Delafloxacin & Fluoroquinolone & FDA-approved & $\begin{array}{l}\text { Klebsiella pneumoniae, including AmpC } \\
\text { and class A ESBL-producers, } \\
\text { ciprofloxacin-resistant Escherichia coli } \\
\text { and A. baumannii }\end{array}$ & ABSSSI \\
\hline Eravacycline & Fluorocycline tetracycline & FDA-approved & ESBL, CRE, MDR A. baumannii & clAl \\
\hline $\begin{array}{l}\text { Imipenem+cilastatin/ } \\
\text { relebactam }\end{array}$ & $\begin{array}{l}\text { Carbapenem/ } \beta \text {-lactamase } \\
\text { inhibitor }\end{array}$ & Phase III & KPC, MDR P. aeruginosa & Not applicable \\
\hline Meropenem/vaborbactam & $\begin{array}{l}\text { Carbapenem/boronic acid } \\
\text { inhibitor }\end{array}$ & FDA-approved & CRE (class A and C enzymes) & cUTI \\
\hline Murepavadin & $\begin{array}{l}\text { Cyclic peptide that targets } \\
\text { outer membrane }\end{array}$ & Phase III & MDR $P$. aeruginosa & Not applicable \\
\hline Omadacycline & Aminomethylcycline & FDA-approved & ESBL, A. baumannii & ABSSSI, CABP \\
\hline Plazomicin & Aminoglycoside & FDA-approved & $\begin{array}{l}\text { ESBL, CRE excluding NDM producers, } \\
\text { A. baumannii, } P \text {. aeruginosa }\end{array}$ & cUTI \\
\hline
\end{tabular}

ABSSSI, acute bacterial skin and skin structure infection; CABP, community-acquired bacterial pneumonia; clAI, complicated intra-abdominal infection; CRE, carbapenem-resistant Enterobacteriaceae; cUTI, complicated urinary tract infection; ESBL, extended-spectrum $\beta$-lactamase; FDA, US Food and Drug Administration; HABP, hospital-acquired bacterial pneumonia; KPC, Klebsiella pneumoniae carbapenemase; MBL, metallo- $\beta$-lactamase; MDR, multidrugresistant; NDM, New Delhi metallo- $\beta$-lactamase; VABP, ventilator-acquired bacterial pneumonia. 
cefiderocol was $0.5 \mathrm{mg} / \mathrm{L}$, which was more active than either tigecycline or colistin ${ }^{63}$. Two phase III clinical trials for cefiderocol-APEKS-NP and CREDIBLE-CR - that include VAP and HAP due to GNB are under way ${ }^{64}$.

Eravacycline was recently approved for the treatment of intraabdominal infections and complicated urinary tract infections (cUTIs). One study showed that against carbapenem- and tigecycline-resistant Acinetobacter isolates, eravacycline MICs were about twofold lower versus comparator agents ${ }^{65}$. However, clinical experience with eravacycline for A. baumannii pneumonia is limited and its role is unclear, especially given evidence of increased adverse events and mortality with tigecycline when prescribed for pneumonia ${ }^{66}$.

Plazomicin is a novel aminoglycoside derived from sisomicin that was modified to resist aminoglycoside-modifying enzymes and is currently approved for use in cUTIs. Significantly improved activity has been observed in OXA-producing A. baumannii compared with other aminoglycosides, and plazomicin MICs are 16 to 32 times lower ${ }^{67}$. A recent clinical trial found favorable results with plazomicin in CRE VAP as well as a favorable safety profile and a low incidence of drug-related adverse events, including serum creatinine elevations ${ }^{68}$. Thus, plazomicin appears promising as part of combination regimens and data on its effectiveness in HAP/VAP due to MDR A. baumannii are eagerly awaited.

Zidebactam and WCK 5153 are two novel $\beta$-lactam antibiotics under development that display high affinity for PBP2 of GNB and overcome multiple $\beta$-lactam resistance mechanisms.
When combined with cefepime or sulbactam, zidebactam and WCK 5153 demonstrated enhanced killing and full bacterial eradication after 24 hours against strains of MDR A. baumannii $^{69}$. Arylomycins are a new class of lipopeptide antibiotics whose lead compound, G0775, was demonstrated to have potent activity against 16 strains of MDR $A$. baumannii ${ }^{70}$. The antibiotic adjuvant SPR741 sensitized A. baumannii to a panel of antibiotics and permitted strong potentiation of rifampin against multiple MDR A. baumannii isolates ${ }^{71}$. Several non-antibiotic therapies against A. baumannii are in various stages of development (for example, bacteriophage, vaccines, and monoclonal antibodies) and have recently been reviewed ${ }^{72}$. Finally, it may be possible in the future to use CRISPR-Cas systems to target plasmids that spread AMR in $\mathrm{GNB}^{73}$.

\section{Conclusions}

Pneumonia due to MDR-GNB represents a serious threat to hospitalized patients. Clinicians must be knowledgeable about local resistance patterns and a patient's risk factors for MDR-GNB to ensure appropriate empiric antimicrobial therapy. Fortunately, several new drugs that target MDR-GNB have been approved or are in late stages of development. Further pragmatic studies are needed to elucidate their place in therapy and their impact on real-world outcomes such as length of stay and mortality, especially for ICU patients with HAP/VAP.

\section{Grant information}

The author(s) declared that no grants were involved in supporting this work.
1. $\quad F$ Thorpe KE, Joski P, Johnston KJ: Antibiotic-Resistant Infection Treatment Costs Have Doubled Since 2002, Now Exceeding \$2 Billion Annually. Health Aff (Millwood). 2018; 37(4): 662-9.

PubMed Abstract | Publisher Full Text | F1000 Recommendation

2. F Kalil AC, Metersky ML, Klompas M, et al:: Management of Adults With Hospital-acquired and Ventilator-associated Pneumonia: 2016 Clinical Practice Guidelines by the Infectious Diseases Society of America and the American Thoracic Society. Clin Infect Dis. 2016; 63(5): e61-e111.

PubMed Abstract | Publisher Full Text | Free Full Text | F1000 Recommendation

3. Bassetti M, Welte T, Wunderink RG: Treatment of Gram-negative pneumonia in the critical care setting: is the beta-lactam antibiotic backbone broken beyond repair? Crit Care. 2016; 20: 19.

PubMed Abstract | Publisher Full Text | Free Full Text

4. Watkins RR, Deresinski S: Using $\beta$-lactam/ $\beta$-lactamase inhibitors for infections due to extended-spectrum $\beta$-lactamase-producing Enterobacteriaceae to slow the emergence of carbapenem-resistant Enterobacteriaceae. Expert Rev Anti Infect Ther. 2017; 15(10): 893-5. PubMed Abstract | Publisher Full Text

5. F Grundmann H, Glasner C, Albiger B, et al:: Occurrence of carbapenemaseproducing Klebsiella pneumoniae and Escherichia coli in the European survey of carbapenemase-producing Enterobacteriaceae (EuSCAPE): a prospective, multinational study. Lancet Infect Dis. 2017; 17(2): 153-63. PubMed Abstract | Publisher Full Text | F1000 Recommendation

6. Vazquez Guillamet C, Kollef MH: Acinetobacter Pneumonia: Improving Outcomes With Early Identification and Appropriate Therapy. Clin Infect Dis. 2018; 67(9): 1455-62. PubMed Abstract | Publisher Full Text
7. Davey PG, Marwick C: Appropriate vs. inappropriate antimicrobial therapy. Clin Microbiol Infect. 2008; 14(Suppl 3): 15-21. PubMed Abstract | Publisher Full Text

8. F Maruyama T, Fujisawa T, Ishida T, et al:: A Therapeutic Strategy for All Pneumonia Patients: A 3-Year Prospective Multicenter- Cohort Study Using Risk Factors for Multidrug Resistant Pathogens To Select Initial Empiric Therapy. Clin Infect Dis. 2018. PubMed Abstract | Publisher Full Text | F1000 Recommendation

9. F Lat I, Daley MJ, Shewale A, et al.: A Multicenter, Prospective, Observational Study to Determine Predictive Factors for Multidrug-Resistant Pneumonia in Critically III Adults: The DEFINE Study. Pharmacotherapy. 2018. PubMed Abstract | Publisher Full Text | F1000 Recommendation

10. Montero M, Sala M, Riu M, et al.: Risk factors for multidrug-resistant Pseudomonas aeruginosa acquisition. Impact of antibiotic use in a double case-control study. Eur J Clin Microbiol Infect Dis. 2010; 29(3): 335-9. PubMed Abstract | Publisher Full Text

11. Gu WJ, Wang F, Tang L, et al.: Colistin for the treatment of ventilatorassociated pneumonia caused by multidrug-resistant Gram-negative bacteria: a systematic review and meta-analysis. Int J Antimicrob Agents. 2014; 44(6): $477-85$

PubMed Abstract | Publisher Full Text

12. F Sader HS, Castanheira M, Mendes RE, et al.: Frequency and antimicrobial usceptibility of Gram-negative bacteria isolated from patients with pneumonia hospitalized in ICUs of US medical centres (2015-17). J Antimicrob Chemother. 2018; 73(11): 3053-9. PubMed Abstract | Publisher Full Text | F1000 Recommendation 
13. Jacoby GA: AmpC beta-lactamases. Clin Microbiol Rev. 2009; 22(1): 161-82 PubMed Abstract | Publisher Full Text | Free Full Text

14. Hauck C, Cober E, Richter SS, et al:: Spectrum of excess mortality due to carbapenem-resistant Klebsiella pneumoniae infections. Clin Microbiol Infect. 2016; 22(6): 513-9

PubMed Abstract | Publisher Full Text | Free Full Text

15. Safdar N, Maki DG: The commonality of risk factors for nosocomia colonization and infection with antimicrobial-resistant Staphylococcus aureus, enterococcus, gram-negative bacilli, Clostridium difficile, and Candida. Ann Intern Med. 2002; 136(11): 834-44. PubMed Abstract | Publisher Full Text

16. F Bassetti M, Carnelutti A, Peghin M: Patient specific risk stratification fo antimicrobial resistance and possible treatment strategies in gram-negative bacterial infections. Expert Rev Anti Infect Ther. 2017; 15(1): 55-65. PubMed Abstract | Publisher Full Text | F1000 Recommendation

17. F Rodríguez-Baño J, Gutiérrez-Gutiérrez B, Machuca I, et al.: Treatment of Infections Caused by Extended-Spectrum-Beta-Lactamase-, AmpC-, and Carbapenemase-Producing Enterobacteriaceae. Clin Microbiol Rev. 2018; 31(2): pii: e00079-17.

PubMed Abstract | Publisher Full Text | Free Full Text | F1000 Recommendation

18. F Harris PNA, Tambyah PA, Lye DC, et al.: Effect of Piperacillin-Tazobactam vs Meropenem on 30-Day Mortality for Patients With E coli or Klebsiella pneumoniae Bloodstream Infection and Ceftriaxone Resistance: A Randomized Clinical Trial JAMA. 2018; 320(10): 984-994. PubMed Abstract | Publisher Full Text | Free Full Text | F1000 Recommendation

19. Tamma PD, Villegas MV: Use of $\beta$-Lactam/ $\beta$-Lactamase Inhibitors for ExtendedSpectrum- $\beta$-Lactamase Infections: Defining the Right Patient Population. Antimicrob Agents Chemother. 2017; 61(8): pii: e01094-17. PubMed Abstract | Publisher Full Text | Free Full Text

20. Zanetti G, Bally F, Greub G, et al:: Cefepime versus imipenem-cilastatin for treatment of nosocomial pneumonia in intensive care unit patients: a multicenter, evaluator-blind, prospective, randomized study. Antimicrob Agents Chemother. 2003; 47(11): 3442-7.

PubMed Abstract | Publisher Full Text | Free Full Text

21. F Cheng L, Nelson BC, Mehta M, et al:: Piperacillin-Tazobactam versus Other Antibacterial Agents for Treatment of Bloodstream Infections Due to AmpC $\beta$-Lactamase-Producing Enterobacteriaceae. Antimicrob Agents Chemother 2017; 61(1): pii: e00276-17.

PubMed Abstract | Publisher Full Text | Free Full Text | F1000 Recommendation

22. Tamma PD, Girdwood SC, Gopaul R, et al:: The use of cefepime for treating AmpC $\beta$-lactamase-producing Enterobacteriaceae. Clin Infect Dis. 2013; 57(6): $781-8$.

PubMed Abstract | Publisher Full Text

23. van Duin D, Doi $Y$ : The global epidemiology of carbapenemase-producing Enterobacteriaceae. Virulence. 2017; 8(4): 460-9. PubMed Abstract | Publisher Full Text | Free Full Text

24. van Duin D, Kaye KS, Neuner EA, et al:: Carbapenem-resistan Enterobacteriaceae: a review of treatment and outcomes. Diagn Microbiol Infect Dis. 2013; 75(2): 115-20.

PubMed Abstract | Publisher Full Text | Free Full Text

25. van Duin D, Bonomo RA: Ceftazidime/Avibactam and Ceftolozane/Tazobactam: Second-generation $\beta$-Lactam/ $\beta$-Lactamase Inhibitor Combinations. Clin Infect Dis. 2016; 63(2): 234-41.

PubMed Abstract | Publisher Full Text | Free Full Text

26. Kaye KS, Vazquez J, Mathers A, et al.: Clinical Outcomes of Serious Infections due to Carbapenem-Resistant Enterobacteriaceae (CRE) in TANGO II, a Phase 3, Randomized, Multi-National, Open-Label Trial of Meropenem-Vaborbactam (M-V) Vs. Best Available Therapy (BAT). Open Forum Infect Dis. 2017; 4(suppl_1) S534-S535.

Publisher Full Text

27. Karaiskos I, Souli M, Giamarellou H: Plazomicin: an investigational therapy for the treatment of urinary tract infections. Expert Opin Investig Drugs. 2015 24(11): 1501-11.

PubMed Abstract | Publisher Full Text

28. $\mathrm{F}$ Zhang $\mathrm{Y}$, Kashikar A, Bush $\mathrm{K}$ : In vitro activity of plazomicin against B-lactamase-producing carbapenem-resistant Enterobacteriaceae (CRE). $J$ Antimicrob Chemother. 2017; 72(10): 2792-5.

PubMed Abstract | Publisher Full Text | F1000 Recommendation

29. F Zhanel GG, Lawrence CK, Adam H, et al:: Imipenem-Relebactam and Meropenem-Vaborbactam: Two Novel Carbapenem- $\beta$-Lactamase Inhibito Combinations. Drugs. 2018; 78(1): 65-98.

PubMed Abstract | Publisher Full Text | F1000 Recommendation

30. Thakare R, Dasgupta A, Chopra S: Eravacycline for the treatment of patients with bacterial infections. Drugs Today (Barc). 2018; 54(4): 245-54. PubMed Abstract | Publisher Full Text

31. van Duin D, Lok JJ, Earley M, et al.: Colistin Versus Ceftazidime-Avibactam in the Treatment of Infections Due to Carbapenem-Resistant Enterobacteriaceae. Clin Infect Dis. 2018: 66(2): 163-71.

PubMed Abstract | Publisher Full Text | Free Full Text

32. Achaogen: Achaogen Announces Positive Results in Phase $\mathbf{3}$ cUTI and CRE Clinical Trials of Plazomicin. Press release 2016.

Reference Source
33. F Torres A, Zhong N, Pachl J, et al.: Ceftazidime-avibactam versus meropenem in nosocomial pneumonia, including ventilator-associated pneumonia (REPROVE): a randomised, double-blind, phase 3 non-inferiority trial. Lancet Infect Dis. 2018; 18(3): 285-95. PubMed Abstract | Publisher Full Text | F1000 Recommendation

34. Mehta M, Uhlemann AC: Beware of broad-spectrum generalizations: ceftazidime-avibactam compared to meropenem for the treatment of gram-negative pneumonia. J Emerg Crit Care Med. 2018; 2: pii: 45. PubMed Abstract | Publisher Full Text | Free Full Text

35. F Bassetti M, Vena A, Croxatto A, et al:: How to manage Pseudomonas aeruginosa infections. Drugs Context. 2018; 7: 212527. PubMed Abstract | Publisher Full Text | Free Full Text | F1000 Recommendation

36. Micek ST, Wunderink RG, Kollef MH, et al:: An international multicenter retrospective study of Pseudomonas aeruginosa nosocomial pneumonia: impact of multidrug resistance. Crit Care. 2015; 19(1): 219. PubMed Abstract | Publisher Full Text | Free Full Text

37. Bauer KA, West JE, O'Brien JM, et al:: Extended-infusion cefepime reduces mortality in patients with Pseudomonas aeruginosa infections. Antimicrob Agents Chemother. 2013; 57(7): 2907-12. PubMed Abstract | Publisher Full Text | Free Full Text

38. Zhanel GG, Chung P, Adam H, et al:: Ceftolozane/tazobactam: a novel cephalosporin/ $\beta$-lactamase inhibitor combination with activity against multidrug-resistant gram-negative bacilli. Drugs. 2014; 74(1): 31-51. PubMed Abstract | Publisher Full Text

39. Xiao AJ, Miller BW, Huntington JA, et al.: Ceftolozane/tazobactam pharmacokinetic/pharmacodynamic-derived dose justification for phase 3 studies in patients with nosocomial pneumonia. J Clin Pharmacol. 2016; 56(1): $56-66$. PubMed Abstract | Publisher Full Text | Free Full Text

40. F Katchanov J, Asar L, Klupp EM, et al.: Carbapenem-resistant Gramnegative pathogens in a German university medical center: Prevalence, clinical implications and the role of novel $\beta$-lactam/ $\beta$-lactamase inhibitor combinations. PLoS One. 2018; 13(4): e0195757. PubMed Abstract | Publisher Full Text | Free Full Text | F1000 Recommendation

41. F Stone GG, Newell P, Gasink LB, et al:: Clinical activity of ceftazidime/ avibactam against MDR Enterobacteriaceae and Pseudomonas aeruginosa: pooled data from the ceftazidime/avibactam Phase III clinical trial programme. pooled data from the ceftazidime/avibactam PubMed Abstract | Publisher Full Text | F1000 Recommendation

42. F Rodríguez-Núñez O, Ripa M, Morata L, et al.: Evaluation of ceftazidime/ avibactam for serious infections due to multidrug-resistant and extensively drug-resistant Pseudomonas aeruginosa. J Glob Antimicrob Resist. 2018; 15 136-9.

PubMed Abstract | Publisher Full Text | F1000 Recommendation

43. Möllmann $\mathrm{U}$, Heinisch L, Bauernfeind A, et al.: Siderophores as drug delivery agents: application of the "Trojan Horse" strategy. Biometals. 2009; 22(4): 615-24.

PubMed Abstract | Publisher Full Text

44. F Dobias J, Dénervaud-Tendon V, Poirel L, et al:: Activity of the novel siderophore cephalosporin cefiderocol against multidrug-resistant Gramnegative pathogens. Eur J Clin Microbiol Infect Dis. 2017; 36(12): 2319-27. PubMed Abstract | Publisher Full Text | F1000 Recommendation

45. Ito A, Kohira N, Bouchillon SK, et al.: In vitro antimicrobial activity of S-649266, a catechol-substituted siderophore cephalosporin, when tested against non-fermenting Gram-negative bacteria. J Antimicrob Chemother. 2016; 71(3): $670-7$.

PubMed Abstract | Publisher Full Text

46. Nguyen L, Garcia J, Gruenberg K, et al.: Multidrug-Resistant Pseudomonas Infections: Hard to Treat, But Hope on the Horizon? Curr Infect Dis Rep. 2018; 20(8): 23

PubMed Abstract | Publisher Full Text

47. F Karlowsky JA, Lob SH, Young K, et al.: Activity of imipenem/relebactam against Pseudomonas aeruginosa with antimicrobial-resistant phenotypes from seven global regions: SMART 2015-2016. J Glob Antimicrob Resist. 2018 15: $140-7$.

PubMed Abstract | Publisher Full Text | F1000 Recommendation

48. F Martin-Loeches I, Dale GE, Torres A: Murepavadin: a new antibiotic class in the pipeline. Expert Rev Anti Infect Ther. 2018; 16(4): 259-68. PubMed Abstract | Publisher Full Text | F1000 Recommendation

49. F Sader HS, Flamm RK, Dale GE, et al:: Murepavadin activity tested against contemporary (2016-17) clinical isolates of XDR Pseudomonas aeruginosa. $J$ Antimicrob Chemother. 2018; 73(9): 2400-4. PubMed Abstract | Publisher Full Text | F1000 Recommendation

50. F Serota DP, Sexton ME, Kraft CS, et al:: Severe Community-Acquired Pneumonia due to Acinetobacter baumannii in North America: Case Report and Review of the Literature. Open Forum Infect Dis. 2018; 5(3): ofy044. PubMed Abstract | Publisher Full Text | Free Full Text | F1000 Recommendation

51. F Cohen B, Liu J, Larson E: Changes in the incidence and antimicrobial susceptibility of healthcare-associated infections in a New York hospital system, 2006-2012. J Prev Med Hyg. 2017; 58(4): E294-E301. PubMed Abstract | Publisher Full Text | Free Full Text | F1000 Recommendation 
52. Guillamet CV, Vazquez R, Noe J, et al.: A cohort study of bacteremic pneumonia: The importance of antibiotic resistance and appropriate initial therapy? Medicine (Baltimore). 2016; 95(35): e4708. PubMed Abstract | Publisher Full Text | Free Full Text

53. F Bickenbach J, Schöneis D, Marx G, et al:: Impact of multidrug-resistant bacteria on outcome in patients with prolonged weaning. BMC Pulm Med 2018; 18(1): 141.

PubMed Abstract | Publisher Full Text | Free Full Text | F1000 Recommendation

54. Zilberberg MD, Nathanson BH, Sulham K, et al:: Multidrug resistance, inappropriate empiric therapy, and hospital mortality in Acinetobacter baumannii pneumonia and sepsis. Crit Care. 2016; 20(1): 221. PubMed Abstract | Publisher Full Text | Free Full Text

55. Garnacho-Montero J, Dimopoulos G, Poulakou G, et al:: Task force on management and prevention of Acinetobacter baumannii infections in the ICU. Intensive Care Med. 2015; 41(12): 2057-75. PubMed Abstract | Publisher Full Text

56. Khawcharoenporn T, Pruetpongpun N, Tiamsak P, et al.: Colistin-based treatment for extensively drug-resistant Acinetobacter baumannii pneumonia. Int $J$ Antimicrob Agents. 2014; 43(4): 378-82. PubMed Abstract | Publisher Full Text

57. F Alp E, Eren E, Elay G, et al:: Efficacy of loading dose of colistin in Acinetobacter baumannii ventilator-associated pneumonia. Infez Med. 2017; 25(4): 311-319.

PubMed Abstract | F1000 Recommendation

58. Lu Q, Luo R, Bodin L, et al:: Efficacy of High-dose Nebulized Colistin in Ventilator-associated Pneumonia Caused by Multidrug-resistant Pseudomonas aeruginosa and Acinetobacter baumannii. Anesthesiology. 2012; 117(6): 1335-47.

PubMed Abstract | Publisher Full Text

59. Pérez-Pedrero MJ, Sánchez-Casado M, Rodríguez-Villar S: Utilización de la colistina nebulizada en la colonización e infección respiratoria por Acinetobacter baumannii en pacientes críticos. Medicina Intensiva. 2011; 35(4): 226-31. Reference Source

60. Li X, Liu L, Ji J, et al:: Tigecycline resistance in Acinetobacter baumannii mediated by frameshift mutation in plsC, encoding 1-acyl-sn-glycerol-3phosphate acyltransferase. Eur J Clin Microbiol Infect Dis. 2015; 34(3): 625-31. PubMed Abstract | Publisher Full Text

61. $\mathrm{F}$ Wright $\mathrm{H}$, Bonomo RA, Paterson DL: New agents for the treatment of infections with Gram-negative bacteria: Restoring the miracle or false dawn? Clin Microbiol Infect. 2017; 23(10): 704-712. PubMed Abstract | Publisher Full Text | F1000 Recommendation

62. F Hackel MA, Tsuji M, Yamano Y, et al.: In Vitro Activity of the Siderophore Cephalosporin, Cefiderocol, against Carbapenem-Nonsusceptible and Multidrug-Resistant Isolates of Gram-Negative Bacilli Collected Worldwide in 2014 to 2016. Antimicrob Agents Chemother. 2018; 62(2): pii: e01968-17. PubMed Abstract | Publisher Full Text | Free Full Text | F1000 Recommendation
63. F Falagas ME, Skalidis T, Vardakas KZ, et al:: Activity of cefiderocol (S-649266) against carbapenem-resistant Gram-negative bacteria collected from inpatients in Greek hospitals. J Antimicrob Chemother. 2017; 72(6): 1704-1708.

PubMed Abstract | Publisher Full Text | F1000 Recommendation

64. Bassetti M, Vena A, Castaldo N, et al.: New antibiotics for ventilator-associated pneumonia. Curr Opin Infect Dis. 2018; 31(2): 177-186.

PubMed Abstract | Publisher Full Text

65. Livermore DM, Mushtaq S, Warner M, et al.: In Vitro Activity of Eravacycline against Carbapenem-Resistant Enterobacteriaceae and Acinetobacter baumannii. Antimicrob Agents Chemother. 2016; 60(6): 3840-4. PubMed Abstract | Publisher Full Text | Free Full Text

66. Shen F, Han Q, Di Xie, et al.: Efficacy and safety of tigecycline for the treatment of severe infectious diseases: an updated meta-analysis of RCTs. Int J Infect Dis. 2015; 39: 25-33. PubMed Abstract | Publisher Full Text

67. García-Salguero C, Rodríguez-Avial I, Picazo JJ, et al.: Can Plazomicin Alone or in Combination $\mathrm{Be}$ a Therapeutic Option against Carbapenem-Resistant Acinetobacter baumannii? Antimicrob Agents Chemother. 2015; 59(10): 5959-66.

PubMed Abstract | Publisher Full Text | Free Full Text

68. Connolly LE, Jubb AM, Keeffe BO, et al.: Plazomicin is associated with improved survival and safety compared to colistin in serious carbapenem-resistant Enterobacteriaceae (CRE) infections: results of the CARE study. Presented at: ASM Microbe; 2017; New Orleans, LA. Reference Source

69. F Moya B, Barcelo IM, Bhagwat S, et al:: Potent $\beta$-Lactam Enhancer Activity of Zidebactam and WCK 5153 against Acinetobacter baumannii, Including Carbapenemase-Producing Clinical Isolates. Antimicrob Agents Chemother. 2017; 61(11): pii: e01238-17.

PubMed Abstract | Publisher Full Text | Free Full Text | F1000 Recommendation

70. F Smith PA, Koehler MFT, Girgis HS, et al:: Optimized arylomycins are a new class of Gram-negative antibiotics. Nature. 2018; 561(7722): 189-94. PubMed Abstract | Publisher Full Text | F1000 Recommendation

71. F Domalaon R, Idowu T, Zhanel GG, et al: Antibiotic Hybrids: the Next Generation of Agents and Adjuvants against Gram-Negative Pathogens? Clin Microbiol Rev. 2018; 31(2): pii: e00077-17.

PubMed Abstract | Publisher Full Text | Free Full Text | F1000 Recommendation

72. Watkins RR: A formidable foe: carbapenem-resistant Acinetobacter baumannii and emerging nonantibiotic therapies. Expert Rev Anti Infect Ther. 2018; 16(8): $591-3$.

PubMed Abstract | Publisher Full Text

73. Bober JR, Beisel CL, Nair NU: Synthetic Biology Approaches to Engineer Probiotics and Members of the Human Microbiota for Biomedical Applications. Annu Rev Biomed Eng. 2018; 20: 277-300.

PubMed Abstract | Publisher Full Text | Free Full Text 


\section{Open Peer Review}

\section{Current Peer Review Status:}

\section{Editorial Note on the Review Process}

Faculty Reviews are review articles written by the prestigious Members of Faculty Opinions. The articles are commissioned and peer reviewed before publication to ensure that the final, published version is comprehensive and accessible. The reviewers who approved the final version are listed with their names and affiliations.

\section{The reviewers who approved this article are:}

\section{Version 1}

\section{Dean Winslow}

Division of Infectious Diseases and Geographic Medicine, Stanford University School of Medicine, Stanford, California, USA

Competing Interests: No competing interests were disclosed.

\section{Frank Schweizer}

Department of Medical Microbiology and Infectious Diseases, University of Manitoba, Winnipeg, Manitoba, Canada

Competing Interests: No competing interests were disclosed.

The benefits of publishing with F1000Research:

- Your article is published within days, with no editorial bias

- You can publish traditional articles, null/negative results, case reports, data notes and more

- The peer review process is transparent and collaborative

- Your article is indexed in PubMed after passing peer review

- Dedicated customer support at every stage

For pre-submission enquiries, contact research@f1000.com

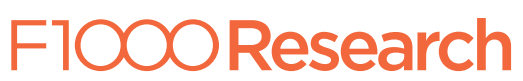

